\title{
Operationalising an effective monitoring and evaluation system for local government: Considerations for best practice
}

\begin{tabular}{|c|c|}
\hline \multicolumn{2}{|c|}{$\begin{array}{l}\text { Authors: } \\
\text { Paul Kariuki }{ }^{1} \\
\text { Purshottama Reddy }{ }^{2}\end{array}$} \\
\hline \multicolumn{2}{|c|}{$\begin{array}{l}\text { Affiliations: } \\
{ }^{1} \text { Democracy Development } \\
\text { Programme (DDP), University } \\
\text { of KwaZulu-Natal, } \\
\text { South Africa }\end{array}$} \\
\hline \multicolumn{2}{|c|}{$\begin{array}{l}{ }^{2} \text { School of Management, IT } \\
\text { and Governance, University } \\
\text { of KwaZulu-Natal, } \\
\text { South Africa }\end{array}$} \\
\hline \multicolumn{2}{|c|}{$\begin{array}{l}\text { Corresponding author: } \\
\text { Paul Kariuki, } \\
\text { pamirry@gmail.com }\end{array}$} \\
\hline \multicolumn{2}{|c|}{$\begin{array}{l}\text { Dates: } \\
\text { Received: } 07 \text { May } 2017 \\
\text { Accepted: } 02 \text { Oct. } 2017 \\
\text { Published: } 16 \text { Nov. } 2017\end{array}$} \\
\hline \multicolumn{2}{|c|}{$\begin{array}{l}\text { How to cite this article: } \\
\text { Kariuki, P., Reddy, P., 2017, } \\
\text { 'Operationalising an effective } \\
\text { monitoring and evaluation } \\
\text { system for local government: } \\
\text { Considerations for best } \\
\text { practice', African Evaluation } \\
\text { Journal 5(2), a240. https:// } \\
\text { doi.org/10.4102/aej.v5i2.240 }\end{array}$} \\
\hline \multicolumn{2}{|c|}{$\begin{array}{l}\text { Copyright: } \\
\text { (C) 2017. The Authors } \\
\text { Licensee: AOSIS. This } \\
\text { is licensed under the } \\
\text { Creative Commons } \\
\text { Attribution License. }\end{array}$} \\
\hline \multicolumn{2}{|l|}{ Read online: } \\
\hline 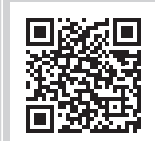 & $\begin{array}{l}\text { Scan this QR } \\
\text { code with your } \\
\text { smart phone or } \\
\text { mobile device } \\
\text { to read online. }\end{array}$ \\
\hline
\end{tabular}

Background: Post-apartheid South Africa faces major challenges in ensuring that it provides high quality and sustainable services that meet citizens' expectations. The public wants local government that is not only responsive to their needs but also provides high quality services equitably to all people irrespective of their socioeconomic status. Sadly, basic services delivery has been on a downward spiral, characterised by ongoing community protests in many local municipalities. The article premises that municipalities need effective monitoring and evaluation systems to operate optimally.

Objectives: The article sought to show that monitoring and evaluation is a critical development tool that needs to be supported by municipal political and administrative leadership to ensure that it functions optimally by offering citizen-responsive services.

Method: The study focused on KwaZulu-Natal province, the second largest province in South Africa, predominantly rural with a significant poverty and underdevelopment. The study utilised a mixed method participatory design, comprising quantitative and qualitative approaches.

Results: The study found that monitoring and evaluation capacity is low in the majority of municipalities besides the Metro. The municipalities were inadequately resourced with competent monitoring and evaluation human personnel, thereby stifling their capacity to deliver quality monitoring and evaluation services.

Conclusion: The article concluded that effective monitoring and evaluation in local government that is responsive to citizens' needs is a non-negotiable imperative for government. It recommended that municipalities be adequately resourced with competent monitoring and evaluation human personnel. This is important for strengthening their capacity to deliver efficient monitoring and evaluation services.

\section{Introduction}

Post-apartheid South Africa faces major challenges in ensuring that it provides high quality and sustainable services that meet citizens' expectations. The public wants local government that is not only responsive to their needs but also provides 'optimal and professional services' across all areas (Meyiwa et al. 2014:4). Thus, government has the onerous responsibility to develop and implement a developmental framework that redresses apartheid legacies. This calls for municipalities to develop proactive responses that free citizens from poverty and underdevelopment.

Historically, local government operated in a manner where one group was more privileged while others were marginalised (Govender 2011:113). Basic services delivery did not cater for all; thus, the democratic government inherited significant backlogs. The new administration adopted a radical transformation policy that aimed to correct the anomalies created by the former regime by ensuring effective public administration. At the same time, it embarked on a programme to educate citizens on human rights, the Constitution and other important pieces of legislation. It was envisaged that this would empower them to demand better, high quality public services and at the same time hold government accountable for its actions (Naidu 2012:279).

Sadly, as the nation has developed over the past two decades, basic services delivery has been on a downward spiral, characterised by ongoing community protests in many local municipalities. According to Govender (2011:6), the root causes of poor service delivery include poor performance culture in many municipalities, a lack of competent technical human resources, political interference and poor financial management as well as an organisational structure that was not aligned. To 
correct these anomalies, the government adopted a peoplecentred framework in 1997, commonly referred to as the 'Batho Pele' (a Sesotho phrase meaning 'people first') principles (GGLN 2012:19). The primary aim of this policy instrument is to encourage public servants to pursue and sustain excellence in basic services provision. Furthermore, the framework aims to transform basic services delivery with regard to service standards, courtesy, information, transparency and openness. It can be argued that these principles facilitate accurate measurement of local government's commitment to deliver sustainable and high quality basic services. For this to become reality, a monitoring and evaluation system is required to enhance corporate governance at the local government level (Hargreaves 2010:35). This article argues that a monitoring and evaluation system is a critical development tool that enhances the legitimacy of this sphere of governance because it ensures that it functions optimally by offering citizen-responsive services. The article is organised as follows: following the introduction in the first section, the second section defines selected key terms specific to the article, followed by a brief discussion on institutionalising monitoring and evaluation in local government in the third section. The fourth section discusses the challenges associated with the institutionalisation of the system, while the fifth explores possible solutions to these challenges and the sixth section briefly examines how to operationalise and sustain an effective municipal-wide monitoring and evaluation system (MWMES). The article concludes by making recommendations and identifying good practices that local municipalities can adopt to maintain an effective monitoring and evaluation system that ensures that basic services are provided efficiently and sustainably.

\section{Definition of key terminology} Monitoring

Monitoring is defined as:

a continuing function that uses systematic collection of data on specified indicators to provide management and the main stakeholders of an ongoing development intervention with indications of the extent of progress and achievement of objectives and progress in the use of allocated funds. (Public Service Commission [PSC] 2008:11)

According to Engela and Ajam (2010:11), monitoring refers to an ongoing process that focuses on assessing whether projects and their routine activities achieve the anticipated results with performance tracked through data collection and reviews. Uys (2010:12) expands this definition, noting that monitoring is a routine internal organisational activity aimed at ensuring that projects deliver their expected results.

\section{Evaluation}

According to Rossi, Lipsey and Freeman (2004:16), evaluation is the systematic application of social research procedures for assessing the conceptualization, design, implementation and utility of social intervention programmes'. The Department of Planning, Monitoring and Evaluation (DPME 2011:vii) understands evaluation as the systematic collection and objective analysis of evidence on public policies, programmes, projects, functions and organisations to assess issues such as relevance, performance (efficiency and effectiveness), value for money, impact and sustainability and recommend the way forward. In this sense, evaluation is a time-bound activity conducted over predetermined periods that compare planned and actual performance (Govender 2011:75).

\section{Interrelationship between monitoring and evaluation}

Conceptually, monitoring and evaluation are complementary activities. While monitoring is a routine activity that assesses an intervention's progress towards the realisation of its goals, evaluation is an in-depth assessment of its value that seeks to determine the reasons for the observable effects of a programme. Therefore, monitoring and evaluation reinforce each other. This is shown in Table 1.

\section{Benefits of monitoring and evaluation in local government}

In broad terms, both monitoring and evaluation activities offer certain benefits if they are conducted correctly and the results are correctly interpreted. In local government, monitoring and evaluation facilitates policy development and proper financial management as well as enabling municipal functionaries to align their interventions with national government's priorities (National Treasury 2010:5). According to Engela and Ajam (2010:11), monitoring and evaluation systems are used to provide information that enables the promotion of good governance and accountability in government.

It follows that monitoring and evaluation provides the necessary impetus to enhance basic services delivery (Schurink \& Schurink 2010:16). While the provision of basic services has remained a continuing challenge in South African local government, renewed understanding of the importance of monitoring and evaluation among public servants could change this situation. Furthermore, public servants are beginning to understand their role in ensuring the timeous achievement of set goals.

TABLE 1: Complementary roles of monitoring and evaluation.

\begin{tabular}{|c|c|}
\hline Monitoring & Evaluation \\
\hline $\begin{array}{l}\text { It is continuous - analysis on the ongoing } \\
\text { progress of a project towards achieving } \\
\text { planned results. }\end{array}$ & $\begin{array}{l}\text { It is periodic-judging the overall merits } \\
\text { of an intervention. }\end{array}$ \\
\hline $\begin{array}{l}\text { Ensures accountability of an } \\
\text { intervention. }\end{array}$ & $\begin{array}{l}\text { Relies more on detailed data for } \\
\text { decision-making. }\end{array}$ \\
\hline Routinely collects data on indicators. & $\begin{array}{l}\text { Assesses the contributions of activities to } \\
\text { results. }\end{array}$ \\
\hline $\begin{array}{l}\text { Translates programme objectives into } \\
\text { performance indicators, capturing } \\
\text { planned results as well. }\end{array}$ & $\begin{array}{l}\text { Captures both intended and unintended } \\
\text { results. }\end{array}$ \\
\hline $\begin{array}{l}\text { Conducted by people usually involved } \\
\text { directly in implementing an } \\
\text { intervention. }\end{array}$ & $\begin{array}{l}\text { Conducted usually by an independent } \\
\text { assessor who is impartial in his or her } \\
\text { judgement of an intervention. }\end{array}$ \\
\hline $\begin{array}{l}\text { Produces regular reports and updates } \\
\text { for management and project staff. }\end{array}$ & $\begin{array}{l}\text { Produces evaluation reports with } \\
\text { suggested recommendations for changes } \\
\text { to an intervention. }\end{array}$ \\
\hline
\end{tabular}

Source: Govender 2011:77 
There is growing appreciation of the fact that the outcomes and impact of government interventions are linked to basic services provision; therefore, local government that is not delivering quality sustainable services is failing in its constitutional mandate. This has prompted national government to implement performance contracts for all public servants, especially those in leadership positions to accurately measure individual staff productivity. The benefits of monitoring and evaluation are summarised in Box 1.

\section{Institutionalisation of monitoring and evaluation in South African local government}

As the sphere of government that is closest to citizens, the Constitution of the Republic of South Africa mandates local government with the responsibility of delivering public services equitably and fairly (Koma 2010:113). The primary aim of this constitutional mandate is to reverse the underdevelopment created by the apartheid regime. In this regard, national government envisages local government that is capable of working with citizens in their locality to address their challenges and provide collaborative, sustainable solutions. However, Davids (2011:3573) notes that many municipalities across the country are struggling to fulfil this mandate, especially given the change from an inward-looking approach, that is, an approach focusing on municipal internal processes, to an outward-looking approach, meaning one that focuses primarily on citizens. Regrettably, most citizens are still wallowing in abject, chronic poverty, while unemployment and inequality are growing apace. The onus is on local government to address these challenges.

In response to this dilemma and in order to improve government performance, the national government developed the Government-Wide Monitoring and Evaluation System. This framework aims to enable national government to improve governance and resource allocation across all departments and agencies. It sets out specific intervention objectives, inputs, outputs, outcomes and expected impact to ensure that government delivers in line with citizens' needs (Presidency, 2011:11). The government envisages a functional and effective public service that:

- facilitates intergovernmental planning

- facilitates cooperative governance in achieving effective and sustained services delivery

- effectively monitors the implementation of government interventions
- continuously and accurately evaluates these interventions to generate insights that inform future interventions, decision-making and policy development

- provides advisory services to government departments with regard to their interventions and suggests corrective actions if they are not delivering the desired results.

It is important to note that the success of this framework depends on support from other key stakeholders who provide oversight of different critical aspects. For instance, the Presidency is responsible for coordinating the implementation of national policies through government departments to ensure integrated service delivery (National Treasury 2010:17). Another key stakeholder is Statistics South Africa, the government agency responsible for collecting and analysing data to generate accurate information to inform government policy planning processes as well as decision-making (Govender 2011:71). The Public Administration Leadership and Management Academy, now the National School of Government, is a critical stakeholder as it is tasked with building the leadership and management capacities of middle and senior government officials, including their knowledge of monitoring and evaluation (Govender 2011). These and other stakeholders, such as the DPME, office of the AuditorGeneral, office of the Premier and the Public Service Commission, need to ensure that government-wide monitoring and evaluation is undertaken responsibly by relevant line departments as shown in Figure 1.

\begin{tabular}{|c|c|c|}
\hline Constitutional Power & Legal Power & Executive Power \\
\hline Auditor-General & National Treasury & \multirow{4}{*}{\begin{tabular}{|l}
\multicolumn{1}{|c|}{ Presidency } \\
National Planning \\
Commission (NPC) \\
- Produce 20-years \\
plan; \\
Department of \\
Performance and \\
Evaluation (DPME) \\
- Produce government- \\
wide frameworks; \\
- Facilitate government \\
five-year plans for \\
priorities; \\
- Monitor and evaluate \\
plans for priorities; \\
- Monitor management \\
practices of \\
government
\end{tabular}} \\
\hline $\begin{array}{l}\text { - Independent monitoring } \\
\text { of compliance; } \\
\text { - Auditing of performance } \\
\text { information; } \\
\text { - Reporting to parliament }\end{array}$ & $\begin{array}{l}\text { - Expenditure reviews; } \\
\text { - Budget and quarterly } \\
\text { financial reporting; } \\
\text { Regulate five-year and } \\
\text { annual plans and } \\
\text { quarterly reporting }\end{array}$ & \\
\hline $\begin{array}{l}\text { Public Service } \\
\text { Commission }\end{array}$ & $\begin{array}{c}\text { Department of } \\
\text { Cooperative Governance } \\
\text { (COGTA) }\end{array}$ & \\
\hline \multirow[t]{2}{*}{$\begin{array}{l}\text { - Independent monitoring } \\
\text { and evaluation of public } \\
\text { service; } \\
\text { - Focus on adherence to } \\
\text { public service principles } \\
\text { in constitutions; } \\
\text { - Reporting to parliament }\end{array}$} & $\begin{array}{l}\text { - Regulate local } \\
\text { government planning; } \\
\text { - Monitor performance } \\
\text { of local government; } \\
\text { - Intervention powers } \\
\text { over local government }\end{array}$ & \\
\hline & $\begin{array}{l}\text { Department of Public } \\
\text { Administration (DPSA) }\end{array}$ & $\begin{array}{l}\text { Line departments } \\
\text { (national/provincial) }\end{array}$ \\
\hline
\end{tabular}

Source: Phillips et al. 2014:394

FIGURE 1: Government departments responsible for monitoring and evaluation in the public service and their source of authority.

BOX 1: Summary of the benefits of a monitoring and evaluation system in local government.

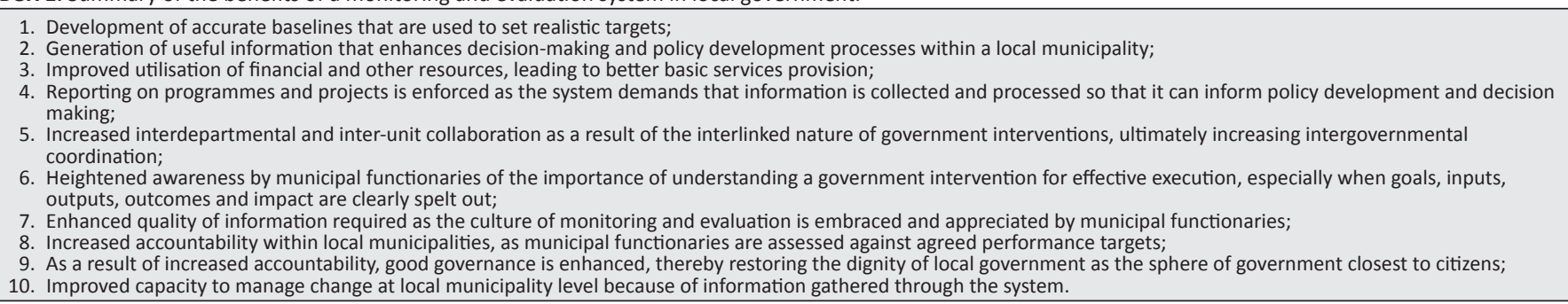
10. Improved capacity to manage change at local municipality level because of information gathered through the system.

Source: Kariuki 2017:211 
At the provincial level, provincial-wide monitoring and evaluation systems are established to ensure that provincial developmental objectives are realised. This includes the coordination of interdepartmental efforts in terms of policy formulation, review and planning as well as overseeing basic services delivery (Govender 2011:106). However, challenges have been reported in institutionalising monitoring and evaluation systems at the provincial level, including complex reporting mechanisms and non-alignment of provincial objectives with national priorities. It is important to note that both national and provincial monitoring and evaluation levels are interlinked and interdependent. They are designed to complement and depend on one another in order to ensure consistency in tracking government performance on its programmes. At local level, the integration of monitoring and evaluation has been fragmented and uncoordinated. Because of a lack of human and financial resources, municipalities have not implemented a MWMES (Govender 2011:107). Monitoring and evaluation have thus notbeen institutionalised at this level. The following section discusses this question.

\section{Challenges associated with the institutionalisation of monitoring and evaluation in South African local government}

As noted in the previous section, an effective monitoring and evaluation system delivers because it is owned by those responsible for leadership at any level of governance. Govender (2011:88) argues that in order to institutionalise a monitoring and evaluation system in a sustainable manner, municipal leadership should appreciate that the system is a critical management tool to guide its performance. That this is not the case at present is demonstrated by the increase in service delivery protests by citizens who are frustrated by the slow pace of basic services provision.

The second challenge associated with the institutionalisation of monitoring and evaluation at the local government level is the lack of competent technical personnel skilled in monitoring and evaluation (Uys 2010:4-5). While significant investment has been made in improving public servants' skills, the State of Municipal Capacity Report for 2010/2011 reveals that major capacity shortfalls persist in most local municipalities (SMCR 2012:8). The deficits are generally higher in rural than urban municipalities (Ajam 2012:4-5). The lack of critical personnel is a catastrophic situation that is a significant impediment to basic services provision.

Thirdly and connected to the above point, most municipalities are unable to accurately align their integrated development plans with the provincial growth and development strategy, which leads to lack of alignment of priorities between municipalities and premiers' offices. Therefore, the vision that municipalities set for themselves is often not realised because of a lack of technical human resource capacity to enable accurate interpretation and subsequent implementation of provincial goals at local government level.
Fourthly, according to the Role of Premiers' Offices in Government-Wide Monitoring and Evaluation Practice Guide: A Good Practice Guide (Presidency 2008:4), there is a general lack of understanding of municipal processes and systems among employees. This poses serious challenges to municipalities insofar as performance management is concerned as the quality of services provided may be compromised. Increased service delivery-related protests may result.

Fifthly, the same guide highlights that the monitoring and evaluation data collected are usually of poor quality and inaccurate (Presidency 2008:4). This suggests that municipalities have significant capacity limitations in generating useful, evidence-based decision-making as a result of a lack of accurate data. It also means that many municipalities will continue lagging behind as far as basic services provision is concerned because they cannot accurately track progress made towards reducing basic services backlogs.

Sixthly, limited understanding of the importance of performance measurement among municipal management and staff is a key impediment to institutionalising monitoring and evaluation in municipalities (Govender \& Reddy 2014b:70). Thus, there is no organisational buy-in to sustain effective monitoring and evaluation practices in local government.

Seventhly, the inertia to change mindset about the way performance measurement has been made has complicated institutionalising monitoring and evaluation in local government (Govender \& Reddy 2014b:70). For a long time, municipal staff have operated within a mindset of the past, 'we have always done things in this way' (Govender \& Reddy 2014b). This kind of mindset resists anything new or change that challenges the status quo. Without a paradigm shift internally with municipal staff and management, institutionalising monitoring and evaluation in local government will remain a distant reality.

While municipalities are complex structures, there is an urgent need to explore ways to address the challenges that are hampering the institutionalisation of monitoring and evaluation at this level. This is based on acknowledgement that monitoring and evaluation is a crucial management and performance tool that helps to assess the impact of government interventions on citizens. The following section discusses the various ways in which these challenges can be mitigated.

\section{Mitigating the challenges associated with the institutionalisation of monitoring and evaluation in local government}

In every challenge lie possibilities for innovation, which normally lead to improved services. The challenges that local municipalities have experienced as they attempt to institutionalise monitoring and evaluation are not uncommon. The main issue is the way institutionalisation should occur to facilitate the process. This section discusses strategies to mitigate the challenges identified. 


\section{Address the systemic factors that beleaguer municipalities by strengthening accountability of municipal leadership in the municipality}

Municipalities are complex structures with numerous actors in their operational space; this complicates the institutional response to citizens' needs. The various interactions are the result of the interdependent nature of local government as it cannot fulfil its mandate in isolation. One systemic factor that plays a significant role in the way municipalities operate is the dwindling revenue base. Many local municipalities, including metros, are constantly exploring innovative ways to increase their revenue to be able to offer better and more sustainable services to citizens. The challenge lies in managing the tension between political mandates and the socioeconomic development agenda that aims to redress the apartheid legacy of underdevelopment. Therefore, while increasing the revenue base through rates and taxes is a sound strategy, systemic issues such as maladministration of resources characterised by corruption must be dealt with decisively by municipalities and the Department of Cooperative Governance and Traditional Affairs (DCOGTA) leadership. Another key systemic issue is the demarcation of areas under municipalities' jurisdiction. Kroukamp and Lues (2008:111) contend that demarcation has increased the distance between municipalities as service providers, and communities as clients. Given the shortage of human resources, municipalities are unable to ensure that all citizens receive equal services without compromising the quality of the services provided. Therefore, by strengthening accountability within the municipality and holding municipal leadership accountable for their performance, systemic challenges will be addressed and eliminated to enhance quality service provision.

\section{Depoliticise municipalities and entrench the culture of evaluation by enforcing independency and transparency of monitoring and evaluation processes}

Municipalities attract significant interest from political parties. For some time, local municipalities have been plagued by intra- and inter-political conflicts as political parties seek to promote their own interests (DCOGTA 2010:4). The net effect of such political interference is polarisation within municipalities that impacts on basic services provision. Because monitoring and evaluation is a highly contested phenomenon in municipalities, municipal leadership should regard it as a management tool aimed at facilitating effective delivery of public services in a responsive manner that matches citizens' needs and expectations. If municipal leadership were to conduct monitoring and evaluation in their municipalities in a way that it promotes respect of independency and transparency of the process, there is a high likelihood that their staff would embrace the practice and inculcate it as part of the organisational norm.

\section{Enhance staff monitoring and evaluation capacity through skilling and re-skilling}

One of the major challenges facing local municipalities is a severe shortage of skills as well as human resources, especially in core technical areas such as information technology and engineering as well as monitoring and evaluation. This situation is dire and can have severe consequences for the entire local government sphere (Govender 2011:123). Local municipalities should prioritise the skilling of their current staff responsible for monitoring and evaluation functions to increase demand for monitoring and evaluation information. This is a policy imperative and should cover all municipalities, rural, peri-urban and urban. At the same time, they should create an environment that attracts and retains technical staff by offering incentives such as training opportunities. The high staff turnover experienced by most local municipalities limits their capacity to deliver effectively on their constitutional mandate.

\section{Enhance intergovernmental and interdepartmental relations for support and oversight}

Another critical element that is necessary for institutionalising monitoring and evaluation in local government is supportive intergovernmental and interdepartmental relations. Intergovernmental interactions enhance work relations among colleagues and help to address challenges at different levels (DCOGTA2010:3). At present, such interactions are fragmented and poorly coordinated, with little oversight offered to local municipalities by DCOGTA at both provincial and national levels. If this aspect is addressed and strengthened, there will be significant sharing of practices and learnings from various interventions, thereby further entrenching a culture of collective responsibility for the results.

\section{Enforce financial accountability in local municipalities}

Financial accountability is critical in both the public and private sectors. It is a governance ingredient that persuades citizens to support a cause with unrelenting commitment. In many municipalities, this virtue is absent; given the atrocious levels of corruption and mismanagement of financial resources, citizens do not feel that officials are concerned about their plight. This situation is exacerbated when no one is held to account and when culprits are let off the hook without being punished or held responsible for their actions. The net effect is very low levels of confidence and trust among citizens (Kariuki, 2017:270).

Municipal leadership supported by law enforcement agencies can stem corruption in local government by enforcing the law as described by the Public Finance and Management Act (PFMA) against illegal activities as well as prosecuting corrupt officials misusing public resources for personal gratification.

\section{Operationalising and sustaining an effective municipal-wide monitoring and evaluation system: Recommendations for good practice}

A sustainable and an effective MWMES is important for a developmental local government. This is because it provides 
a framework of operation that guides municipalities to deliver their interventions according to set objectives and targets while being cognizant of citizen's needs. Therefore, to ensure that an effective MWMES is established and sustained, the following aspects need to be considered:

- Municipal leadership should address the challenge of political and administrative bureaucracy in its system which often stifles innovation. Bureaucracy in this case constitutes the polity responsible for executing established policies by politicians (Olumuyiwa 2015:7). It concerns itself with policy implementation and policymaking. While these duo responsibilities are critical for effective municipal functioning, they sometimes stand in the way of innovation especially as it relates to implementing systems such as monitoring and evaluation aimed at improving systemic efficiencies. MWMES is an innovative mechanism aimed at improving local governance through provision of quality public services that meet citizens' expectations. If municipal political and administrative leadership, which often is responsible for policy implementation, is not enthusiastic about supporting MWMES, it will hinder its successful establishment in municipalities. Thus, the crucial task of municipal leadership is to find out what barriers stand in the way of efficiency and address them to ensure municipal services are delivered resourcefully (Koma 2010:115).

- Municipal political leadership should be cognizant of the costs associated with implementing and sustaining a results-oriented MWMES and plan accordingly to ensure quality service provision. Some of the critical costs to consider include attracting and retaining qualified and experienced monitoring and evaluation human resources who assist the municipalities in quality reporting about interventions to enhance decisionmaking processes. Knowing these costs upfront and associated benefits of a results-based monitoring and evaluation system will enable the municipal political leadership to plan better and support monitoring and evaluation units in their work.

- Strengthen intergovernmental relations to enhance utilisation of monitoring and evaluation systems in supporting municipalities to deliver on their mandates. Essentially, cooperative governance means that all the three spheres of government should work together (cooperate) to provide citizens with a comprehensive package of services (co-relationship) (Khawula 2016:13). While the cooperative governance is an important concept for ensuring an integrated and coherent government, there are inherent weaknesses within the national and provincial departments of Cooperative Governance and Traditional Affairs (COGTA) (Motingoe 2012:204). Some of these weaknesses include lack of interdepartmental coordination, limited information sharing among departments as well as limited municipal consultation by provinces on draft provincial policies and laws (Mpisi 2013:8). Many key provincial policies and laws affecting municipalities are passed without municipalities' participation (Jordaan \& Fourie 2013:25). These weaknesses impact on municipalities' capacity to render their services efficiently to citizens. To address these weaknesses, effective interlinkage between national and provincial COGTA departments is recommended. The provincial COGTA department then connects with municipalities to ensure they are capable to interpret government programmes and support them to implement them successfully (DCOGTA 2010:4).

- Connected to the above point, to ensure that MWMES is sustained, a strong municipal political leadership promoting utilisation of monitoring and evaluation data is needed. This leadership is needed because it has the capacity to build and strengthen interdepartmental trust so that data can be shared across different units to enhance interdepartmental cooperation (Govender \& Reddy 2014b:174). This cooperation is important for strategic policy development in municipalities because of effective data management systems. A coordinated data management system lessens duplication of information, thereby minimising errors in decision-making processes. It is imperative for the monitoring and evaluation unit of a municipality to ensure that data quality at every phase of the data management process (data sourcing, data collection, data collation, data analysis, data reporting and data use) is of high quality. Data must be accurate, reliable, exact, comprehensive, timely and of high integrity, meaning data that are not biased or manipulated.

- Connected to the above point, it is imperative to strengthen municipal monitoring and evaluation information systems. This would mean that, with time, quality data will be collected and analysed accurately to provide insights that inform decision-making, budgeting processes and policy development, among other aspects of municipal governance. Moreover, this would increase demand for monitoring and evaluation information as well as its utilisation.

- Create a strong performance culture with effective rewards and sanctions (Engela \& Ajam 2010:14). It is important that rewards are linked to performance to ensure agreed goals and deliverables are met. Essentially, the achievement of set goals and the standard of performance to which the goals have been achieved are the two main sets of criteria for determining rewards (Bussin 2017:23). This implies that the way a municipal employee meets the defined norms of quality determines the reward due to them. In a similar vein, every municipality should have a clearly defined policy that defines the consequences of non-performance.

- As a norm, municipalities should always conduct baseline assessments before implementing government programmes. In most cases, local municipalities lack the necessary baseline data to inform their interventions (Engela \& Ajam 2010:18). It is imperative that local municipalities establish systems that capture critical data that are subjected to stringent verification processes to ensure their authenticity. They are then processed to inform decision making and other pertinent governance processes.

- Develop technology-responsive systems that will facilitate proper and accurate reporting of municipal 
interventions (Govender \& Reddy 2014a:71). An example of such technologies includes electronic data dashboards and other web-based information systems that facilitate real-time collection of monitoring and evaluation data. They can produce reports timeously that can be integrated with other reports generated from non-electronic systems. It is important that all data-producing mechanisms be integrated with existing data management processes to enhance coherent reporting and decision-making in municipalities.

In summary, operating an efficient and sustainable MWMES requires significant coordination of multiple role players to ensure it delivers results as expected. However, it also requires a significant level of support from political and administrative leadership at the municipal level, who should work in tandem with each other to ensure they support municipalities in delivering quality public services.

\section{Conclusion}

Monitoring and evaluation is critical for ensuring that local government that is responsive to citizens' needs. Admittedly, there is no one-size-fits-all approach for tackling the challenges facing local government. However, to create conditions for improvement and sustained good performance of the sector, both political and administrative leadership in municipalities must work with each other in delivering their services to the public sustainably. They must also possess requisite technical skills and competencies in order to execute municipal monitoring and evaluation responsibilities with discretion and sensitivity.

Moreover, the three spheres of government need to work more closely to ensure an integrated effective and efficient service delivery. Monitoring and evaluation plays a crucial role in connecting these spheres through a coordinated linking of critical activities such as information flow interdepartmentally to ensure accurate reporting of government programmes. This means intergovernmental relations among these governance spheres must be strong to ensure mutual accountability.

To realise this ideal on a consistent basis, there must be a commitment geared towards embracing municipal-wide monitoring and evaluation as a tool for enabling a resultsoriented developmental local government. In pursuit of a developmental local government, municipalities must prioritise upskilling and re-skilling their human resources (municipal officials), in order to standardise performance and outputs from the system. This implies that there should be better coordination of monitoring and evaluation efforts across departments and units, to ensure timely and effective decision-making for better outcomes. To this end, monitoring and evaluation in municipalities needs to move beyond compliance towards institutionalisation in an incremental way, to improve monitoring and evaluation practice in the sector. The implementation of monitoring and evaluation systems contributes to the pursuit of good governance. Failure to move towards institutionalisation means that monitoring and evaluation practice in municipalities is reduced to a mere checklist exercise. Ultimately, the ability of municipalities to be accountable may be compromised.

\section{Acknowledgements Competing interests}

We declare that we have no financial or personal relationships that may have inappropriately influenced us in writing this article.

\section{Authors' contributions}

P.K. conducted the research, analysed the findings and wrote the paper for publication and also actioned all the revisions for the manuscript as requested by the Editor. P.R. supervised the research and quality assured the paper to ensure it is appropriate for submission.

\section{References}

Ajam, T., 2012, 'Proposals on municipal capacity building: Doing things differently or re-packaging the past initiatives', in Dullar Omar Institute (ed.), Local Government Bulletin, pp. 1-16, Community Law Centre, Cape Town.

Bussin, M., 2017, Performance management reboot, KR Publishing, Randburg.

Davids, G.J., 2011, 'Local government capacity challenges in post-apartheid South Africa: Lessons learnt', African Journal of Business Management 5(7), 3570-3576.

Department of Co-operative Governance \& Traditional Affairs (DCOGTA), 2010, KwaZulu-Natal Provincial Government, Toolkit: Performance Management Made simple, DCOGTA, Pretoria, pp. 3-4.

Department of Planning, Monitoring and Evaluation (DPME), 2012, Evaluation Competency Framework for Government, The Presidency, DPME, Pretoria.

Engela, R. \& Ajam, T., 2010, Implementing a government- wide monitoring and evaluation system in South Africa, ECD Working Paper Series, No. 21, The World Bank, Washington, DC, pp. 11, 14, 18.

Good Governance Learning Network (GGLN), 2012, Advancing active citizenship: A Citizenship Academy as a means to strengthen local democracy?, A Discussion Paper and Roundtable Report, GGLN, Cape Town, pp. 15-20.

Govender, I., 2011, 'Monitoring and evaluation systems enhancing corporate governance in local government: A case study of KwaZulu-Natal', unpublished doctoral thesis, Public Administration, School of Public Administration and Development Management, Faculty of Management Studies, University of KwaZulu-Natal, pp. 6, 106, 107, 113, 123.
Kwalo

Govender, I. \& Reddy, P., 2014a, 'Monitoring and evaluation in local municipalities: A case study of KwaZulu-Natal Province', Administratio Publica 160(22), 4.

Govender, N. \& Reddy, P., 2014b, 'Performance monitoring and evaluation. The eThekwini experience, South Africa', African Journal of Public Affairs 7(1), 58-79.

Hargreaves, M.B., 2010, Evaluating systems change: A planning guide, Mathematica, Policy Research Inc., Princeton, NJ, p. 35.

Jordaan, J. \& Fourie, D., 2013, 'Towards best practice financial performance management: A platform design for stewardship in public administration', African Journal of Public Affairs 6(1), 19-40.

Kariuki, P., 2017, 'Developing a human resource framework for monitoring and evaluation personnel in selected municipalities of KwaZulu-Natal', unpublished doctoral thesis, Public Administration, School of Management, IT and Governance, Faculty of Management Studies, University of KwaZulu-Natal.

Khawula, B., 2016, 'An evaluation of community participation in the integrated development planning (IDP) process: A case study of Umzumbe municipality in the province of Kwazulu-Natal in South AFRICA', unpublished master's thesis, Public Management, Faculty of Public Management and Economics, Durban University of Technology.

Koma, S.B., 2010, 'The State of Local Government in South Africa: Issues, trends and options', Journal of Public Administration 45(1.1), 111-120.

Kroukamp, H. \& Lues, L., 2008, 'Improving local management', in M.S. de Vries, P.S. Reddy \& M. Haque (eds.), Improving local government: Outcomes of comparative research, p. 111, Governance and Public Management Series, Oxford Press, London, England.

Meyiwa, T., Nkondo, M., Chitiga-Mabugu, M., Sithole, M. \& Nyamnjoh, F., 2014, State of the nation 2014. South Africa 1994-2014: A twenty-year review, HSRC Press, Cape Town. 
Motingoe, R.S., 2012, 'Monitoring and evaluation system utilisation for municipa support', unpublished doctoral thesis, Degree of Public Management and Governance, Potchefstroom campus, North-West University.

Mpisi, M., 2013, The model of inter-governmental relations: Presentation in the Technical Premier's Co-ordinating Forum on 29 November 2014 in Durban, KwaZulu Natal Premiers Office, Durban.

Naidu, R., 2012, 'Subduing local voice-public participation and ward committees', in S. Booysen (ed.), Local elections in South Africa: Parties, people, politics, pp. 279293, SUN MeDIA MeTRO, Bloemfontein.

National Treasury, 2010, Treasury guidelines: Preparation of expenditure estimates for the 2011 medium term expenditure framework, National Treasury, Pretoria, p. 5.

Olumuyiwa, A., 2015, 'Bureaucratic politics and policy development: Issues and challenges', African Journal of Political Science and International Relations 10(2), 16-24.

Phillips, S., Goldman, I., Gasa, N., Akhalwaya, I. \& Leon, B., 2014, 'A focus on M\&E of results: An example from the Presidency, South Africa', Journal of Development Effectiveness 6(4), 392-406.
Presidency, 2008, The role of premiers' Offices in government wide monitoring and evaluation: A good practice guide, Presidency, Pretoria.

Schurink, W. \& Schurink, E., 2010, 'Outcomes-based evaluation within a systems perspective: Moving beyond a theory of change to system change reform in public governance', Administration Publica 18(2), 13-38.

Public Service Commission (PSC), 2008, Basic concepts in monitoring and evaluation, PSC, Pretoria.

Rossi, P., Lipsey, M. \& Freeman, H., 2004, Evaluation: A systematic approach, 7th edn., SAGE, Thousand Oaks, CA.

State of Municipal Capacity Report (SMCR), 2012, State of municipal capacity report (SMCR) for the 2010/11 financial year, viewed 06 September 2014, from www. dplg.gov.za

The Presidency, Republic of South Africa, 2011, National Evaluation Policy Framework, The Presidency, Pretoria, p. 11.

Uys, F.M., 2010, 'Improving performance in the public sector', Administration Publica $18(2), 54-73$. 